\title{
Recovery of nerve conduction after a pneumatic tourniquet: observations on the hind-limb of the baboon ${ }^{1}$
}

\author{
T. J. FOWLER, G. DANTA, AND R. W. Gilliatt \\ From the Institute of Neurology, Queen Square, London
}

SUMMARY A small pneumatic cuff inflated around the knee was used to produce tourniquet $\frac{0}{\partial}$ paralysis in baboons. A cuff pressure of $1,000 \mathrm{~mm} \mathrm{Hg}$ maintained for one to three hours produced $\frac{\varrho}{2}$ paralysis of distal muscles lasting up to three months. Nerve conduction studies showed that most of ${ }^{\infty}$ the motor fibres to the abductor hallucis muscle were blocked at the level of the cuff and that they conducted impulses normally in their distal parts. There was a significant correlation between the duration of compression and that of the subsequent conduction block. When tested two to three weeks after the tourniquet, the amplitude of the response of $\mathrm{m}$. abductor hallucis to nerve stimulation distal to the cuff was usually slightly reduced compared with the precompression figure. This was? assumed to mean that a small proportion of the motor fibres had undergone Wallerian degeneration on as a result of compression. Maximal motor conduction velocity was reduced in recovering nerves. was also reduced when a cuff pressure of $500 \mathrm{~mm} \mathrm{Hg}$ was used, which was insufficient to produç $\mathbb{W}_{\infty}^{\circ}$ persistent conduction block. In such cases a reduced velocity without evidence of block could be demonstrated 24 hours after compression. Ascending nerve action potentials were recorded from the sciatic nerve in the thigh, with stimulation at the ankle. Before compression the fastest afferen fibres had a significantly higher velocity than the fastest motor fibres in the same nerve trunk. Resulg $\overrightarrow{0}$ after compression suggested that the high-velocity afferent fibres had a susceptibility to the procedure similar to that of the fastest motor fibres.

In clinical practice, particularly in orthopaedic surgery, it is well recognized that the application of a tourniquet to a limb is sometimes followed by paralysis which may persist for weeks or months. While most of the reports in the literature date from the period when rubber tubing or Esmarch bandages were used (Lejars, 1912; Eckhoff, 1931), occasional examples have been reported after pneumatic tourniquets (Bruner, 1951; Moldaver, 1954). In severe cases there may be widespread Wallerian degeneration of nerves below the level of the tourniquet, with wasting of muscles, and a long delay before recovery begins. In milder cases there is a local conduction block under the tourniquet, without Wallerian degeneration, without wasting of muscles, and with recovery after a few weeks. This form of local conduction block was investigated in cats

\footnotetext{
1 This work was supported by the Medical Research Council.
}

by Denny-Brown and Brenner in 1944. They found that there was local demyelination of nerve fibres under the tourniquet but no loss of axonal continuity through the lesion. The electrical excitability of the motor nerves distal to the tourniquet was preserved, and in most cases power in the affected muscles recovered within a few weeks. Conduction velocity during the recovery period was studied by Mayer and Denny-Brown (1964) who found it to be reduced at the site of the tourniquet compared with the velocity above and below this level.

In the present experiments we have reinvestigated the conduction block produced by a tourniquet, with special reference to the timecourse of recovery. In baboons it has been $\frac{D}{0}$ possible to apply a pneumatic cuff rather than the narrower rubber tubing used by Mayer and $N$ Denny-Brown in the cat. Recovery in individual $N$ 638 
animals has been followed by serial nerve conduction studies similar to those used previously to study animals with experimental toxic polyneuropathy (Hern, 1971; Hopkins and Gilliatt, 1971). A brief preliminary account of our results has already been published (Danta, Fowler, and Gilliatt, 1971).

\section{METHODS}

All experiments were carried out on sexually mature female baboons (Papio papio) their body weights ranging from 8.6 to $14.9 \mathrm{~kg}$. The animals were fed on a solid pellet diet (Spillers) with added fruit and milk. Monthly injections of cyanocobalamin were also given. As a tourniquet, a small sphygmomanometer cuff (Accoson) designed for an infant was used. The canvas sleeve was specially reinforced to withstand pressures of $1,000 \mathrm{~mm} \mathrm{Hg}$. The rubber bag measured $10 \times 5 \mathrm{~cm}$ and was applied with its long axis round the lower limb at the level of the knee, with the bag overlying the popliteal fossa; when inflated its width was slightly increased to $5.5 \mathrm{~cm}$.

Nerve conduction was examined in the medial popliteal branch of the sciatic nerve. For the motor studies the stimulating cathodes were stainless steel needles placed close to the sciatic nerve in the thigh, and close to the posterior tibial nerve below the knee and at the ankle (Fig. 1). Muscle action potentials were recorded from the abductor hallucis muscle, the active recording electrode being a subcutaneous needle over the muscle belly and the remote electrode a subcutaneous needle near the base of the second digit.

Ascending nerve action potentials were recorded through a needle electrode close to the sciatic nerve in the thigh, a remote electrode being placed over the quadriceps muscle; stimuli were delivered to the posterior tibial nerve behind the medial malleolus. Nerve and muscle action potentials were amplified by a conventional R-C coupled amplifier and displayed on one beam of a Tektronix 502 oscilloscope, the other beam being used to provide a time-scale. The stimulus intensity was adjusted to be approximately $20 \%$ greater than that necessary to produce a maximal response on the oscilloscope. Single and superimposed sweeps were photographed on $35 \mathrm{~mm}$ film. In addition, ascending nerve action potentials were recorded on magnetic tape and subsequently averaged in a Biomac 500 digital computer. For both nerve and muscle action potentials, latency was measured to the onset of the negative deflection. When measurements of muscle action potential amplitude were made, the height of the negative deflection of the action potential was used.
Anaesthesia for the application of the tourniquet and for the nerve conduction studies was provided by an initial tranquillizing dose of phencyclidine $(2 \mathrm{mg} / \mathrm{kg}$ ) and promazine $(1 \mathrm{mg} / \mathrm{kg})$, followed by intravenous pentobarbitone sodium $(60-120 \mathrm{mg}$, depending on the duration of the experiment).

To ensure that nerve cooling did not take place during the conduction studies, animals were covered with a thick layer of cotton wool and the exposed limb was warmed by a lamp. Room temperature was maintained above $24^{\circ} \mathrm{C}$. Intramuscular temperature in the calf was measured with a thermistor and varied between $35.4^{\circ}$ and $39 \cdot 2^{\circ} \mathrm{C}$ in different experiments.

\section{RESULTS}

CLINICAL EFFECTS OF COMPRESSION In most animals a cuff pressure of $1,000 \mathrm{~mm} \mathrm{Hg}$ was used and was maintained for periods of one to three hours. In a few cases compression at $500 \mathrm{~mm}$ for two hours was tried, but these animals appeared to recover normal use of the leg within 24 hours, although electrophysiological studies indicated that some residual nerve damage was present. In contrast to this, a cuff pressure of $1,000 \mathrm{~mm} \mathrm{Hg}$ was sufficient to produce paralysis of distal muscles, which long outlasted the duration of nerve compression.

Some animals were killed for histology within a few days or weeks, but 10 animals were kept under observation after compression at 1,000 $\mathrm{mm} \mathrm{Hg}$ until substantial clinical and electrophysiological recovery had occurred, the period of observation varying from 28 to 279 days. In two of the 10 cases (compression for 60 and 110 minutes) the animals were only mildly disabled (B22R, B27R). Although there was foot drop and loss of toe grip, both animals started to take weight on the affected foot within a few days, and muscle weakness disappeared within two to four weeks. There were four severely affected animals (compression for 150 and 180 minutes) which showed foot drop and loss of toe grip accompanied by a reluctance to bear weight on the affected foot lasting about three weeks; full movement of the toes when gripping and climbing in the cage did not return for three months (B15, B28, B33, B34). In these animals some wasting of the muscles of the affected leg and foot appeared, and examination under anaesthesia at a later stage showed mild contracture, with limitation of passive plantar-flexion and 


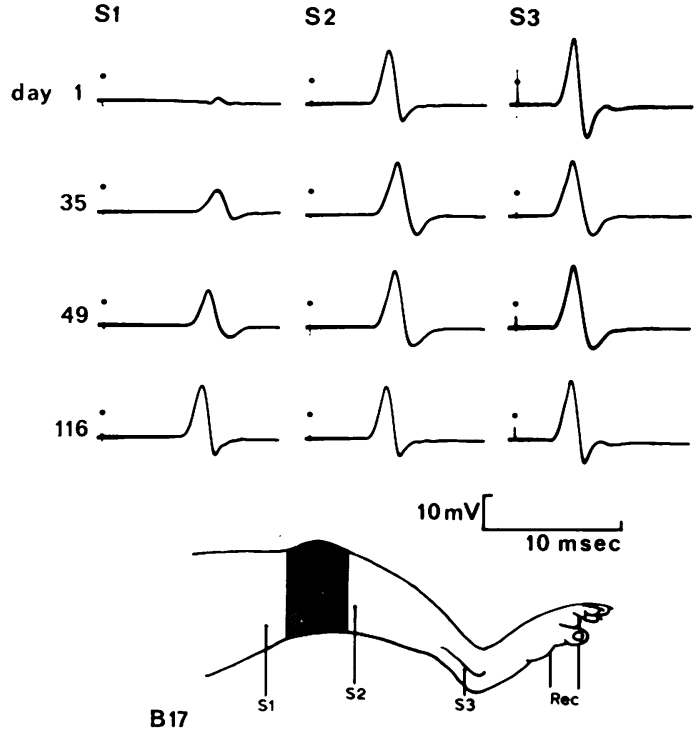

FIG. 1. Evoked muscle action potentials from abductor hallucis muscle at different intervals after $a$ tourniquet inflated to $1,000 \mathrm{~mm} \mathrm{Hg}$ round the knee for 95 minutes. Sites of stimulating and recording electrodes shown below. dorsiflexion of the foot. The remaining animals $\underline{\bar{c}}$ showed a deficit intermediate in severity between $\underset{\mathbb{D}}{Z}$ the two groups described above. In all cases appreciation of pin-prick on the affected foot of appeared to be preserved throughout the period of observation.

RECOVERY OF MOTOR NERVE CONDUCTION Control estimations of maximal motor conduction $\stackrel{2}{2}$ velocity and response amplitude were carried out in all animals before the tourniquet was applied. $\stackrel{\sim}{\stackrel{F}{~}}$ No recordings were made during the period of ? nerve compression or immediately after release $\frac{\bar{\sigma}}{\bar{\omega}}$ of the tourniquet. Some animals were examined $\overparen{\nabla}$ after 24 hours, but in others with severe paralysis the first post-tourniquet recording was deferred o until the second or third week.

All nerves compressed at $1,000 \mathrm{~mm} \mathrm{Hg}$ for one $\overrightarrow{\vec{\omega}}$ hour or longer showed evidence of conduction $ᄋ$ block. A typical result is shown in Fig. 1. It can be seen that on the day after the tourniquet the muscle response to maximal nerve stimulation in the thigh was reduced to a small fraction of the response to stimulation below the level of the $\mathbb{\infty}_{\infty}$

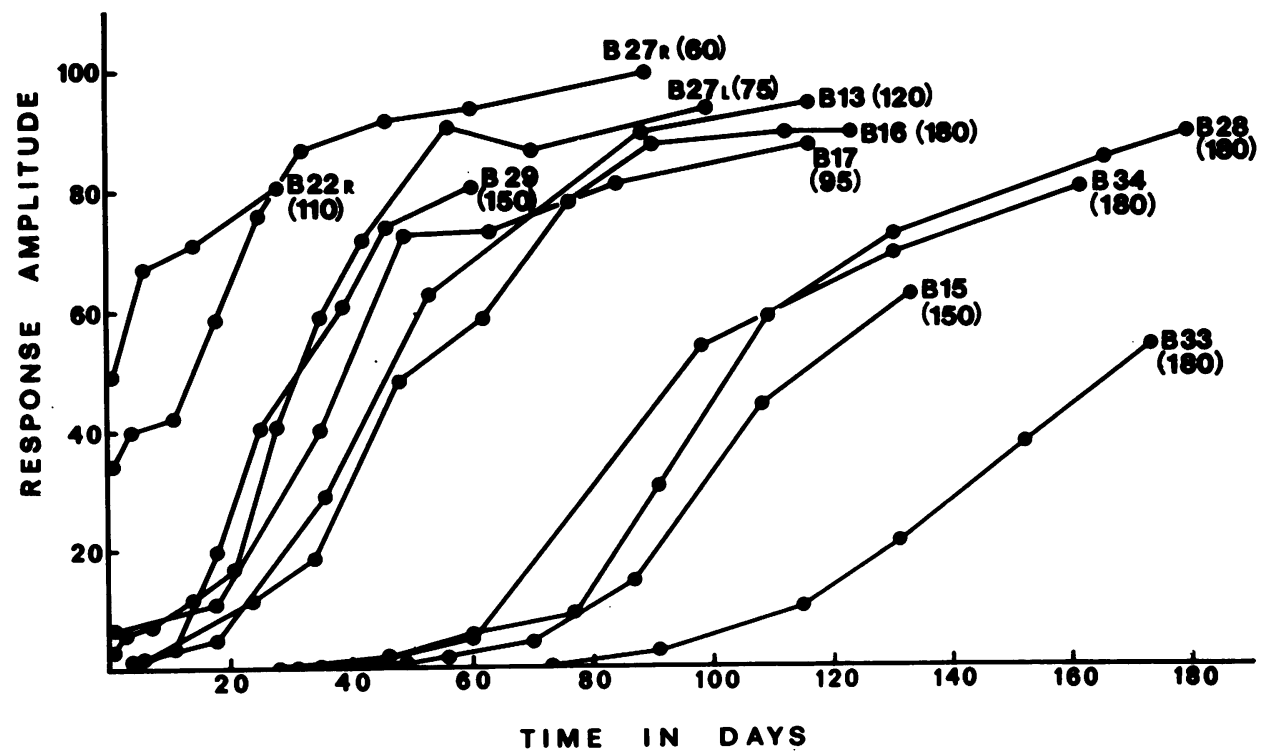

FIG. 2. Recovery after conduction block produced by a tourniquet in 11 nerves. Muscle action potentials recorded from abductor hallucis muscle, with motor nerve stimulation in thigh and at ankle. On vertical scale, amplitude of muscle response to proximal stimulation as percentage of response to distal stimulation. Horizontal scale, time in days after tourniquet. Animal number and duration of tourniquet in minutes shown for each nerve. 
cuff. Gradual recovery was seen in serial records, a normal response to stimulation in the thigh being obtained by the 116th day. Recovery curves for 11 nerves from 10 animals are shown in Fig. 2. The number in parentheses against each curve is the duration of compression in minutes. The pressure in the cuff was approximately $1,000 \mathrm{~mm} \mathrm{Hg}$ in each case. The response amplitude shown on the vertical scale of Fig. 2 is not the absolute amplitude of the muscle response to nerve stimulation in the thigh, but this figure as a percentage of the response to ankle stimulation in the same experiment. By the use of this ratio, changes in response amplitude due to slight variations in the position of the recording electrodes on different occasions are eliminated.

It can be seen from Fig. 2 that there was considerable variation in the severity of the conduction block and in the rapidity of recovery in different animals. Some of the differences between animals appeared to be related to the duration of compression. Thus the two nerves which were least affected were compressed for only 60 and 110 minutes, whereas the four nerves which took longest to recover were subjected to compression for 150 or 180 minutes. When the time to $50 \%$ recovery in Fig. 2 is matched with the duration of the compression, using Spearman's ranking test, this correlation is significant at the 0.01 level $(r=0.82)$.

While most of the nerve fibres subjected to compression appeared to conduct normally distal to the site of the cuff, there was evidence that a small number underwent Wallerian degeneration. Thus, muscle wasting was seen in the more severely affected animals and fibrillation was present when these muscles were sampled with a coaxial needle electrode.

The amount of Wallerian degeneration in each case could be estimated roughly by comparing the amplitude of the muscle response to nerve stimulation at the ankle before the tourniquet with the response two to four weeks after compression-that is, long enough after injury for Wallerian degeneration to have occurred. Such a comparison is shown in Table 1 .

The amplitude of muscle action potentials recorded on two successive occasions varies in a random fashion due to slight differences in the position of the recording electrodes, but Table 1
TABLE 1

AMPLITUDE OF MUSCLE ACTION POTENTIALS RECORDED FROM ABDUCTOR HALLUCIS MUSCLE IN RESPONSE TO MOTOR NERVE STIMULATION AT ANKLE (VALUES BEFORE AND 14-24 DAYS AFTER A TOURNIQUET AT KNEE)

\begin{tabular}{|c|c|c|c|c|}
\hline \multirow[t]{2}{*}{ Nerve } & \multirow{2}{*}{$\begin{array}{l}\text { Duration of } \\
\text { tourniquet } \\
\quad(\text { min) }\end{array}$} & \multicolumn{2}{|c|}{$M A P$ amplitude $(m V)$} & \multirow[t]{2}{*}{$\%$ change } \\
\hline & & Before & After & \\
\hline B27R & 60 & 20.9 & $24 \cdot 1$ & +15 \\
\hline B27L & 75 & $24 \cdot 1$ & 23.6 & -2 \\
\hline B17 & 95 & $22 \cdot 7$ & $16 \cdot 8$ & -26 \\
\hline B22R & 110 & $16 \cdot 3$ & $18 \cdot 6$ & +14 \\
\hline B13 & 120 & $27 \cdot 8$ & $21 \cdot 4$ & -23 \\
\hline B29 & 150 & $25 \cdot 5$ & $26 \cdot 2$ & +3 \\
\hline B15 & 150 & $27 \cdot 7$ & $21 \cdot 8$ & -21 \\
\hline B16 & 180 & $27 \cdot 8$ & $16 \cdot 4$ & -41 \\
\hline B28 & 180 & $22 \cdot 8$ & 20.4 & -10.5 \\
\hline B33 & 180 & $14 \cdot 5$ & 13.6 & -6 \\
\hline B34 & 180 & 20.9 & $14 \cdot 5$ & -30.5 \\
\hline Mean & $134 \cdot 5$ & $22 \cdot 8$ & 19.8 & $-11 \cdot 6$ \\
\hline
\end{tabular}

Student's $t$ test on 11 pairs: $\mathrm{P}<0.05$.

shows a statistically significant fall in amplitude after nerve compression, this fall being greatest in the animals subject to the longest periods of compression. For these four animals (compression for 180 minutes), the mean fall in response amplitude was $22 \%$ compared with $11.6 \%$ for the group as a whole.

In the least affected animals (compression for
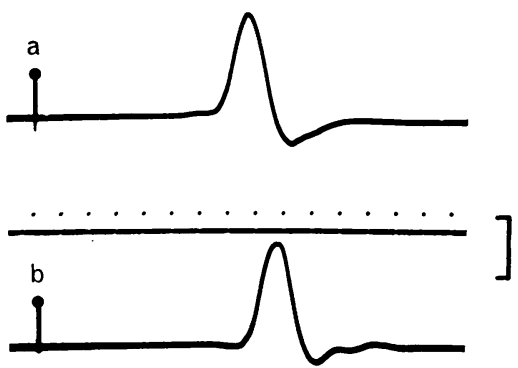

$\mathrm{msec}$

FIG. 3. B26. Tourniquet at $500 \mathrm{~mm} \mathbf{H g}$ for 120 minutes. Evoked muscle action potentials from abductor hallucis muscle (a) immediately before compression and (b) on following day, to show increase in latency without loss of response amplitude. Calibration $10 \mathrm{mV}$. Conduction distance from stimulating cathode in thigh to muscle was approximately $33 \mathrm{~cm}$ on each occasion. 
60 and 110 minutes) response amplitude was actually slightly increased after compression, this change being within the range of variation which may occur in paired control observations on the same nerve (cf. Table 3 of Hopkins and Gilliatt, 1971). Muscle sampling for fibrillation was not carried out in these two animals, but the conduction studies do not suggest that the local block at the site of the tourniquet was accompanied by Wallerian degeneration.

In contrast with the experiments described above, in which a cuff pressure of $1,000 \mathrm{~mm} \mathrm{Hg}$ was used, there were three animals in which a pressure of $500 \mathrm{~mm} \mathrm{Hg}$ for two hours was tried. Illustrative records from one animal are shown in Fig. 3. The muscle response to nerve stimulation in the thigh immediately before compression is shown above, and the response 24 hours later is shown below. It can be seen that there was little change in the amplitude of the response as a result of compression, although its latency was increased. Similar results were obtained for the other two nerves compressed at $500 \mathrm{~mm} \mathrm{Hg}$ (see Table 6). From this it appears that compression insufficient to cause a significant conduction block may still result in a persistent conduction delay in the affected fibres.

TABLE 2

EFFECT OF TOURNIQUET AT KNEE ON MAXIMAL VELOCITY IN MOTOR FIBRES TO ABDUCTOR HALLUCIS MUSCLE

\begin{tabular}{lcccc}
\hline & $\begin{array}{c}\text { Nerves } \\
(\text { no. })\end{array}$ & \multicolumn{2}{c}{ Velocity $(\mathrm{m} / \mathrm{sec})$} \\
\cline { 3 - 5 } & & Range & Mean & $S D$ \\
\hline $\begin{array}{l}\text { Thigh to below knee } \\
\text { Control nerves } \\
\text { After tourniquet } \\
\text { early }\end{array}$ & 26 & $60 \cdot 4-84 \cdot 5$ & $70 \cdot 3$ & $6 \cdot 7$ \\
$\quad$ late & 11 & $13 \cdot 8-44 \cdot 0$ & $29 \cdot 0$ & $10 \cdot 2$ \\
$\begin{array}{l}\text { Below knee to ankle } \\
\quad \begin{array}{l}\text { Control nerves } \\
\text { After tourniquet } \\
\text { early }\end{array}\end{array}$ & 10 & $44 \cdot 3-62 \cdot 5$ & $55 \cdot 1$ & $7 \cdot 0$ \\
$\quad$ late & 11 & $56 \cdot 7-79 \cdot 0$ & $65 \cdot 8$ & 8.4 \\
\hline
\end{tabular}

Table 2 shows the effect of compression on maximal motor velocity in the 11 nerves illustrated in Fig. 2. In this Table the first velocity obtained after the tourniquet is labelled 'early'. In mildly affected animals this early velocity was obtainable 24 hours after compression, whereaŝ in severely affected cases with prolonged anco complete conduction block, up to 45 days్ elapsed before velocity could be estimated. From? Table 2 it can be seen that maximal velocity through the compressed segment was initially decreased, values for the 11 nerves ranging from 13.8 to $44.0 \mathrm{~m} / \mathrm{sec}$ with a mean of $29.0 \mathrm{~m} / \mathrm{sec}$. Corresponding figures for the range of contro $\overrightarrow{\mathrm{F}}$ values were $60.4-84.5 \mathrm{~m} / \mathrm{sec}$; mean $70.3 \mathrm{~m} / \mathrm{sec}$. $\Rightarrow$

The 'late' velocities shown in Table 2 were those obtained at the last recording on each nerve shown in Fig. 2. The time after compres $\overline{\bar{n}}$. sion ranged from 28 days for the least affected, nerve to 180 days for the severely affected. It can be seen that the mean late velocity for the group? was significantly reduced compared with the control mean. Analysis of individual results showed that in five nerves the velocity was still below the lower limit of the control range at the end of the period of observation.

In contrast with the reduction in velocity through the compressed segment, the me帅is maximal motor velocity in nerve distal to the cuff did not show a significant change from the control mean in either the early or the late gro@p of observations after the tourniquet.

Figure 4 shows muscle action potentiå용 evoked by thigh stimulation before compression (above), and during the early recovery peris

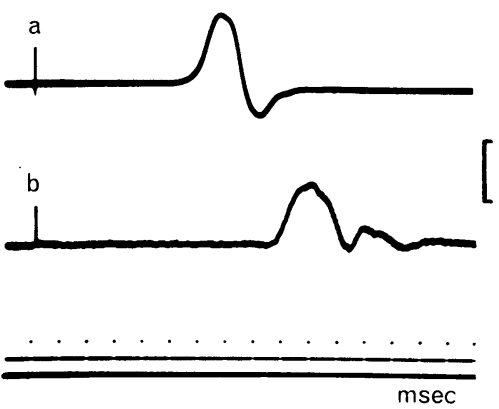

FIG. 4. B33. Tourniquet at $1,000 \mathrm{~mm} \mathrm{Hg}$ for $180 \varrho$ minutes. Evoked muscle action potentials from abductor hallucis muscle (a) before and (b) 73 days after compression, to show temporal dispersion during $\rightarrow$ early recovery period. Calibration bar represents $10 \mathrm{mV}$ for upper and $200 \mu \mathrm{V}$ for lower trace. Conduc- N tion distance from stimulating cathode in thigh to muscle was approximately $30 \mathrm{~cm}$. 
(below). The nerve had been compressed for 180 minutes and the lower record was taken after an interval of 73 days; at this time, response amplitude was still less than $2 \%$ of the precompression figure. It can be seen that, in addition to an increase in latency, there was temporal dispersion of the response.

Dispersion was seen only in the early stages of recovery of severely affected nerves. In mildly affected nerves and in the later stages of recovery of severely affected nerves, the duration of the muscle action potentials did not appear to be increased.

To confirm that the reduced amplitude of the muscle action potentials during the recovery period was due to long-lasting conduction block and not to temporal dispersion of impulses in recovering fibres, muscle action potential area was measured before compression and during recovery. In Table 3 the amplitude and the area of the muscle response to thigh stimulation are shown as percentages of the values obtained with ankle stimulation in the same experiment. Both measurements refer to the negative deflection of the response. In control observations on 11 nerves before compression, the mean amplitude of the response to thigh stimulation was $89.1 \%$ of the amplitude obtained by ankle stimulation, whereas the corresponding figure for area was $98.9 \%$. This suggests that in normal nerves the

\section{TABLE 3}

RELATION BETWEEN AMPLITUDE AND AREA OF MUSCLE ACTION POTENTIALS RECORDED BEFORE AND AFTER TOURNIQUET (IN EACH CASE THE RESULTS OF PROXIMAL STIMULATION ARE GIVEN AS PERCENTAGES OF THOSE OBTAINED BY DISTAL STIMULATION)

\begin{tabular}{|c|c|c|c|c|c|}
\hline \multirow[t]{2}{*}{ Nerve } & \multicolumn{2}{|c|}{ Before tourniquet } & \multicolumn{3}{|c|}{ After tourniquet } \\
\hline & Amp. & Area & Days & Amp. & Area \\
\hline B13 & 94 & 92 & 53 & 63 & $47 \cdot 2$ \\
\hline B15 & 98 & 110 & 108 & 44 & $37 \cdot 5$ \\
\hline B16 & 90 & $93 \cdot 5$ & 48 & 48 & 36.4 \\
\hline B 17 & 86 & $102 \cdot 6$ & 35 & 40 & $42 \cdot 5$ \\
\hline B22R & 83 & 104 & 1 & 49 & 58 \\
\hline B27L & $92 \cdot 5$ & $101 \cdot 5$ & 35 & 59 & $57 \cdot 5$ \\
\hline B27R & $89 \cdot 5$ & 103 & 18 & 58.5 & 57 \\
\hline B28 & 92 & 91 & 109 & 59 & 57 \\
\hline B29 & 90 & $88 \cdot 5$ & 25 & 40 & 44.5 \\
\hline B33 & 78.5 & $98 \cdot 5$ & 173 & 54 & $59 \cdot 2$ \\
\hline B34 & 87 & $103 \cdot 2$ & 98 & 55 & $61 \cdot \overline{4}$ \\
\hline Mean & $89 \cdot 1$ & 98.9 & 64 & $51 \cdot 7$ & $50 \cdot 7$ \\
\hline
\end{tabular}

conduction distance between thigh and ankle allows some dispersion which results in a slight reduction in the amplitude of the response but not in its area. To obtain corresponding values during recovery, the records showing approximately $50 \%$ recovery of amplitude in the 11 nerves were measured in the same way. Results are given in Table 3, from which it can be seen that the mean amplitude of the muscle response to thigh stimulation was $51.7 \%$ of the amplitude obtained by ankle stimulation, whereas the corresponding figure for area was $50.7 \%$. These figures agree so closely that dispersion cannot be said to have contributed significantly to the reduced amplitude of the muscle action potentials at this time. It seems that the reduction in both amplitude and area of the thigh responses in the recovering nerves was due to long-lasting conduction block.

ASCENDING NERVE ACTION POTENTIALS BEFORE AND AFTER COMPRESSION Ascending nerve action potentials (NAPs) were recorded from 21 control nerves in 12 animals. In each case motor nerve stimulation was carried out first, and maximal motor velocity calculated. The needle electrode placed close to the sciatic nerve in the thigh for motor nerve stimulation was subsequently used for recording the ascending NAP, and the stimulating cathode at the ankle was unchanged throughout. In this way, maximal velocity in motor and afferent fibres could be compared in the same nerve during the same experiment and over the same distance. Results from 21 control nerves are shown in Table 4, from which it can be seen that velocity in the fastest afferent fibres ranged from 74.2 to $89.0 \mathrm{~m} / \mathrm{sec}$ with a mean of $80.9 \mathrm{~m} / \mathrm{sec}$, compared with a range of 60.0 $77.0 \mathrm{~m} / \mathrm{sec}$ and a mean of $68.5 \mathrm{~m} / \mathrm{sec}$ for the fastest motor fibres. The difference in the mean velocities of the two groups is significant at the 0.01 level. The higher maximal velocity of afferent fibres in this nerve is in keeping with previous observations on other limb nerves in the baboon (McLeod and Wray, 1967; Hopkins and Gilliatt, 1971).

Ascending NAPs were recorded from 12 nerves in 10 animals before and after compression by a tourniquet. Three nerves (B30L, B33, B34) were compressed at $1,000 \mathrm{~mm} \mathrm{Hg}$ for 180 minutes. In the first few weeks after compression 
TABLE 4

VELOCITY IN FASTEST MOTOR AND AFFERENT FIBRES OF MEDIAL POPLITEAL NERVE BETWEEN THIGH AND ANKLE (CONTROL OBSERVATIONS ON 21 NERVES)

\begin{tabular}{lccc}
\hline & \multicolumn{3}{c}{ Velocity $(\mathrm{m} / \mathrm{sec})$} \\
\cline { 2 - 4 } & Range & Mean & $S D$ \\
\hline Motor & $60 \cdot 0-77 \cdot 0$ & $68 \cdot 5$ & $4 \cdot 0$ \\
Afferent & $74 \cdot 2-89.0$ & 80.9 & $3 \cdot 5$ \\
\hline
\end{tabular}

of these three nerves, no muscle action potentials (MAPs) could be recorded from abductor hallucis in response to motor nerve stimulation in the thigh, and no NAPs could be recorded in the thigh with stimulation at the ankle. MAPs were first recorded on the 24th, 39th, and 45th days, and NAPs on the 38th, 60th, and 115th days (Table 5). By the time NAPs were first recorded, the MAPs had recovered to $1 \cdot 1,6 \cdot 1$, and $13.6 \%$ of their pre-compression amplitude.

In four nerves compressed at $1,000 \mathrm{~mm} \mathrm{Hg}$ for 90-120 minutes, a small MAP was present within the first two weeks after compression. At this time no NAP could be recorded. Only one of the animals was followed until the NAP reappeared. Results for this animal (B35) are shown in Table 5 from which it can be seen that the NAP was first recorded on the 46th day. By this time the MAP had recovered to $11 \%$ of its pre-compression amplitude.

TABLE 5

TIME TO REAPPEARANCE OF MUSCLE AND NERVE ACTION POTENTIALS AFTER TOURNIQUET

\begin{tabular}{lccc}
\hline Nerve & $\begin{array}{c}\text { Duration of } \\
\text { tourniquet (min) }\end{array}$ & $\begin{array}{c}\text { Daj, on which } \\
\text { MAP first secn }\end{array}$ & $\begin{array}{c}\text { Day on which } \\
\text { NAP first scen }\end{array}$ \\
\hline B30L & 180 & 24 & 38 \\
B33 & 180 & 45 & 115 \\
B34 & 180 & 39 & 60 \\
B35 & 120 & 4 & 46 \\
\hline
\end{tabular}

The results shown in Table 5 should not be taken to imply that afferent fibres were more severely affected by compression than motor fibres. It is likely that recovery of conduction in only one or two motor fibres supplying abductor hallucis would be sufficient to give rise to detectable MAP. Indeed, some of the MAP $Z$ shown in Table 5 had an amplitude similar tof that of single motor unit potentials evoked been threshold stimulation in control animals. In cons trast with this, NAPs depend upon synchronouse activity in a number of fibres, and we would no expect to record them if only a few fibres were़े. conducting through the lesion. Dispersion of impulses in different fibres might also contribute to the late reappearance of NAPs after com $\stackrel{?}{-}$ pression. Evidence that some dispersion of ascending volleys was present in the early re $\frac{\bar{\sigma}}{\mathrm{s}}$. covery phase of severely affected nerves can be seen in Fig. 5, which shows the post-compression NAPs from the most severely affected nerve in ${ }^{\text {s }}$ our series. The rise-time of the negative deflection $\vec{P}$ of the action potential can be seen to be slightly $\vec{\omega}$

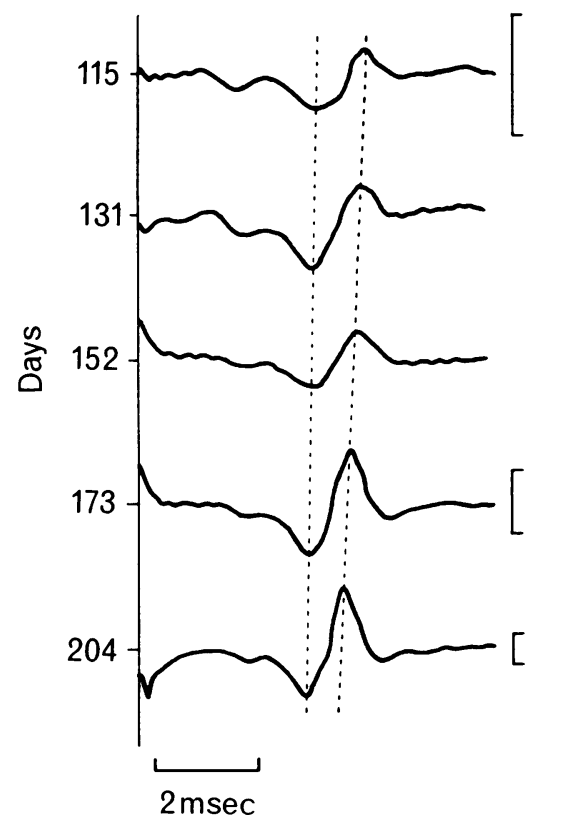

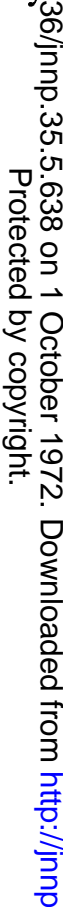

FIG. 5. B33. Ascending nerve action potentials recorded from thigh, with stimulation at ankle, at. different intervals after a tourniquet at $1,000 \mathrm{~mm} \mathrm{Hg} \bigcirc$ for 180 minutes. Each tracing is the average of 128 responses. Calibration $10 \mu \mathrm{V}$. Conduction distance $\mathrm{S}$ $21 \cdot 5-23.25 \mathrm{~cm}$ on different occasions. The broken $>$ lines indicate a gradual decrease in the latency and? rise-time of the potentials during recovery. (Pre-ñ compression values for latency were $2.7 \mathrm{msec}$ to inflexion, $3 \cdot 3$ msec to peak). 
increased in the early stages of recovery and to return towards normal in later records.

No comparable increase in the rise-time of NAPs occurred in the mildly affected nerves (Fig. 6). Results from five such nerves are shown

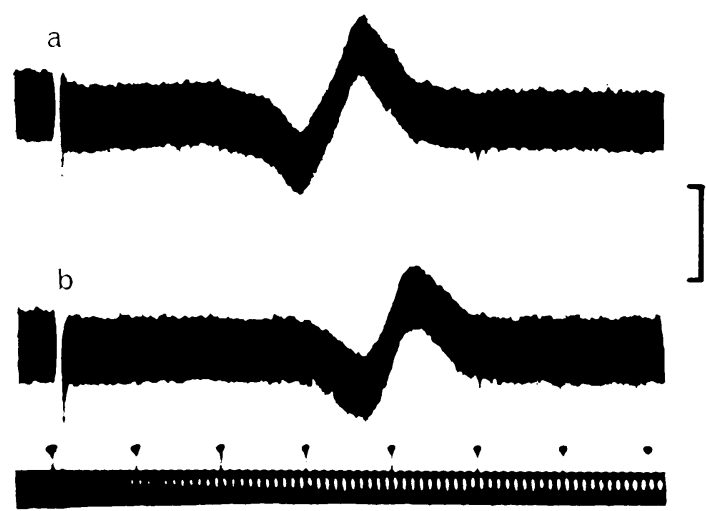

msec

FIG. 6. B26. Tourniquet at $500 \mathrm{~mm} \mathrm{Hg}$ for 120 minutes. Ascending nerve action potentials recorded from thigh, with stimulation at ankle (a) immediately. before compression and (b) on following day, to show increase in latency without dispersion. Calibration $20 \mu \mathrm{V} .100$ faint traces superimposed. Conduction distance $22 \cdot 5-23 \cdot 5 \mathrm{~cm}$.

\section{TABLE 6}

AMPLITUDE OF MUSCLE AND NERVE ACTION POTENTIALS, AND VELOCITY OF FASTEST MOTOR AND AFFERENT FIBRES IN FIVE MILDLY AFFECTED NERVES (IN EACH CASF AMPLITUDE AND VELOCITY IS GIVEN AS PERCENTAGE OF PRE-TOURNIQUET FIGURE)

\begin{tabular}{|c|c|c|c|c|c|c|c|}
\hline \multirow[t]{3}{*}{ Verce } & \multicolumn{2}{|c|}{ Tourniquet } & \multirow{3}{*}{$\begin{array}{c}\text { Days } \\
\text { after } \\
\text { tourni- } \\
\text { que't }\end{array}$} & \multirow{2}{*}{\multicolumn{2}{|c|}{$\begin{array}{c}\text { Amplitude } \\
\left({ }^{\circ}{ }^{\circ}\right)\end{array}$}} & \multirow{2}{*}{\multicolumn{2}{|c|}{$\begin{array}{c}\text { Max. velocity } \\
(0.0)\end{array}$}} \\
\hline & \multirow{2}{*}{$\begin{array}{l}\text { Pressure } \\
(m m \mathrm{Hg})\end{array}$} & \multirow{2}{*}{$\begin{array}{l}\text { Duration } \\
(\text { min })\end{array}$} & & & & & \\
\hline & & & & $M A P$ & $\triangle A P$ & Motor & Afferent \\
\hline B4 IL & 1.000 & 90 & 4 & $1 \cdot 1$ & $33 \cdot 5$ & $74 \cdot 0$ & $71 \cdot 6$ \\
\hline B32R & 1.000 & 120 & 6 & $2 \cdot 5$ & $51 \cdot 0$ & $56 \cdot 5$ & $55 \cdot 0$ \\
\hline B26L & 500 & 120 & 1 & $100 \cdot 0$ & $80 \cdot 0$ & $83 \cdot 5$ & $83 \cdot 2$ \\
\hline B30R & 500 & 120 & 1 & 103.0 & $81 \cdot 0$ & 85.0 & $67 \cdot 5$ \\
\hline $\mathrm{B} 40 \mathrm{~L}$ & 500 & 120 & 2 & 91.5 & 42.5 & $79 \cdot 0$ & $78 \cdot 1$ \\
\hline
\end{tabular}

in Table 6. In each case MAPs and NAPs were present at the first examination after compression. In two nerves compressed at $1.000 \mathrm{~mm} \mathrm{Hg}$. the reduction in size of MAPs was greater than that of NAPs, whereas in three nerves compressed at $500 \mathrm{~mm} \mathrm{Hg}$ the reverse was true. It is clear from Hopkins and Gilliatt (1971) that the amplitude of both MAPs and NAPs shows substantial random variation in successive examinations. Values for conduction velocity obtained on different occasions show less variation and might therefore be expected to provide a more accurate indication of the severity of nerve damage. From Table 6 it can be seen that in each case the percentage reduction in velocity after compression was similar for the fastest-conducting motor and afferent fibres. This makes it unlikely that there was a systematic difference in their susceptibility to compression.

\section{DISCUSSION}

Our results are in good agreement with those of Denny-Brown and Brenner (1944) who first showed that a tourniquet applied to the hind limb of the cat at pressures of $450-1,200 \mathrm{~mm} \mathrm{Hg}$ would produce a persistent conduction block, with preservation of excitability in the distal part of the nerve. In their experiments muscle weakness usually recovered within two to three weeks, but in a later paper by Mayer and Denny-Brown (1964) it was noted that, although most animals showed marked improvement in power by 12-16 days, reflex toe-spreading might remain abnormal until the fourth or fifth week. In the present experiments muscle weakness and conduction block have sometimes lasted for even longer periods. For example, in our severely affected animals some weakness of toe movement lasted for approximately three months. From Fig. 2 it can be seen that in these animals few of the motor fibres to $\mathrm{m}$. abductor hallucis had recovered from conduction block after two months and that some fibres were still blocked after four months.

This delay in recovery is interesting in relation to clinical descriptions of tourniquet paralysis in man. Moldaver (1954) carried out serial observations on two patients who developed complete paralysis of the muscles supplied by the median, ulnar, and radial nerves after surgery in which tourniquets were used. Nerve stimulation above the site of the tourniquet failed to produce a visible twitch on the 38th day after injury in one patient and on the 41 st day in the other, although normal twitches were easily elicited by stimula- 
tion below this level. Recovery of muscle twitches evoked by stimulation above the site of injury was first seen after 49 days, and was complete by 100 days in both cases. In some clinical accounts of patients with tourniquet paralysis, it is likely that there was considerable Wallerian degeneration in addition to conduction block. In such cases much longer delays in recovery were seen, for example in case 5 of Eckhoff (1931) and in case 2 of Richards (1954). In the three patients described by Speigel and Lewin (1945) there also appears to have been extensive Wallerian degeneration, and no recovery occurred during the period of observation.

In the present experiments the results of nerve stimulation suggest that Wallerian degeneration affected only a small proportion of the motor fibres to $\mathrm{m}$. abductor hallucis, and that the slow recovery of response amplitude which was observed was due to long-lasting conduction block. It should be emphasized that regeneration after Wallerian degeneration could not have contributed to the recovery of muscle action potential amplitude in our study. The distance from the lower border of the cuff to the abductor hallucis muscle was $20-25 \mathrm{~cm}$. Unpublished experiments on regeneration after nerve crush in the baboon have shown that regeneration over this distance may be expected to take three months; even after this time the muscle response has a latency greatly in excess of those observed in the present series. It is certainly remarkable that a local block can persist for several months after an episode of acute compression. This problem will be discussed elsewhere in relation to the anatomical findings (Ochoa, Fowler, and Gilliatt, to be published).

Although we were able to show that there was a significant correlation between the duration of compression at $1000 \mathrm{~mm} \mathrm{Hg}$ and the severity of the resulting conduction block, it is clear from Fig. 2 that individual animals varied considerably in their susceptibility to the procedure. For example, compression for 180 minutes was used in both B16 and B33; in the former, recovery of response amplitude to approximately $50 \%$ had occurred after 50 days, whereas in the latter it took 167 days. Individual variation of this kind would certainly be expected from the clinical literature, which contains many examples of paralysis occurring after short periods of com- pression which were thought to be safe on the basis of previous experience in other patients. If most of these cases rubber tubing or an Esmarch bandage was used, and the pressure applied to the limb probably varied from patient to patien (for discussion, see Hinman, 1945). Our own results show that when the pressure is kept con stant, there is still considerable variation if individual susceptibility.

The effect of a pneumatic cuff on the under lying nerve depends not only on the cuff pressure and its duration, but also on the size of the cuff ie relation to the size of the limb, and the amount of muscle overlying and protecting the nerve Denny-Brown and Brenner (1944) and Lundborg (1970) have shown that the pressure in the tissues in the region of the nerve may be substantiall $\vec{\phi}$ less than that in the encircling cuff. In any cas $\overrightarrow{\mathrm{e}}$ this pressure is trivial compared with that needef to block conduction when an isolated nerve wholly enclosed in a pressure chamber (Gruncक fest, 1936). How then does pressure produce longlasting nerve damage? Does it prodttce? secondary ischaemia by the occlusion of snia blood vessels, as suggested by Denny-Brown $\mathbb{1}$ Brenner (1944) and other authors? Our o\&va conclusion, based upon the anatomical findire is that the major factor is not ischaemia but ghe pressure gradient in the nerve between its coin pressed and uncompressed parts. This result in longitudinal movement of the axon and its myelin from the site of compression, and in occlusion of the nodes of Ranvier due to dislocas tion of paranodal myelin, these lesions bein concentrated at the edges of the compressed zono (Ochoa, Danta, Fowler, and Gilliatt, 1971).

The observation that conduction velocity reduced in nerves recovering from the effects of compression was first made by Mayer and Denny-Brown (1964). Their animals were studied two weeks after compression, and the author attributed the velocity change to the demyelinas tion which was conspicuous at this time. In the present series, however, a reduced conduction. velocity has sometimes been recorded as early aS 24 hours after release of the cuff. This is too early for the classical appearance of demyelinas tion to be present, and some other explanatio for the velocity change must be sought. It seems: likely that both the conduction block and the reduced velocity are caused by the occlusion of 
the nodes of Ranvier and the paranodal invagination which are present during the first few days after compression. This problem will be discussed elsewhere in relation to the anatomical findings (Ochoa et al., to be published).

It is interesting that our results do not indicate a consistent difference in the susceptibility of fast-conducting motor and afferent fibres to compression. The relative sparing of sensation which occurs in many different types of human pressure palsy may, however, be due to the sparing of small-diameter afferent fibres (Seddon, 1943). While we have made no relevant physiological observations on this point, our anatomical results confirm that there is relative sparing of small myelinated and unmyelinated fibres. In view of this, it is not surprising that touch and pain sensation should frequently be preserved.

One general point should be made in relation to the measurement of conduction velocity through a local lesion such as the one described here. The method which has been used for measuring maximal motor conduction velocity may be expected to give information about the fastest-conducting motor fibres provided that they can be excited by the stimulus at all levels in the nerve trunk. If, however, the fastest fibres are blocked completely by the lesion, so that only slowly-conducting fibres are excited by stimuli proximal to this level, then the calculated maximal velocity will be misleading. For example, the 'early' velocities shown in Table 2 were obtained at a time when most of the motor fibres to $\mathrm{m}$. abductor hallucis were blocked at the level of the lesion. Thus, although maximal shocks were used, stimulation proximal and distal to the lesion did not excite the same fibre population. For this reason the figures do not provide valid information about velocity changes in individual fibres.

In the animals subjected to compression at $500 \mathrm{~mm} \mathrm{Hg}$, however, there was little or no fall in muscle action potential amplitude and, presumably, little or no conduction block. The velocity changes in these three nerves may thus be accepted as a true indication of the changes occurring in the fastest motor fibres. It can be seen from Table 6 that velocity fell to $83.5 \%$, $85 \%$, and $79 \%$ of the precompression value in each case. These figures were calculated for conduction distances of $21 \cdot 5-23 \cdot 5 \mathrm{~cm}$ between the thigh and ankle. However, only $5.5 \mathrm{~cm}$ of the nerve would have been beneath the pneumatic cuff. If the velocity changes were limited to this $5.5 \mathrm{~cm}$ length, the true velocity through the lesion might have been as low as $50-60 \%$ of normal, although these nerves were the least affected in our series. Further experiments are planned to obtain comparable figures for single fibres in more severely affected nerves.

We wish to thank Dr. R. G. Willison for helpful criticism, and Mr. P. Fitch for technical assistance.

\section{REFERENCES}

Bruner, J. M. (1951). Safety factors in the use of pneumatic tourniquet for hemostasis in surgery of the hand. Journal of Bone and Joint Surgery, 33-A, 221-224.

Danta, G., Fowler, T. J., and Gilliatt, R. W. (1971). Conduction block after a pneumatic tourniquet. Journal of Physiology, 215, 50-52P.

Denny-Brown, D., and Brenner, C. (1944). Paralysis of nerve induced by direct pressure and by tourniquet. Archives of Neurology and Psychiatry, 51, 1-26.

Eckhoff, N. L. (1931). Tourniquet paralysis. Lancet, 2, 343345.

Grundfest, H. (1936). Effects of hydrostatic pressures upon the excitability, the recovery, and the potential sequence of frog nerve. Cold Spring Harbor Symposia on Quantitative Biology, 4, 179-187.

Hern, J. E. C. (1971). Some Effects of Experimental Organophosphorus Intoxication in Primates. DM Thesis: University of Oxford.

Hinman, F., Jr. (1945). The rational use of tourniquets. International Abstracts of Surgery, 81, 357-366.

Hopkins, A. P., and Gilliatt, R. W. (1971). Motor and sensory nerve conduction velocity in the baboon: normal values and changes during acrylamide neuropathy. Journal of Neurology, Neurosurgery, and Psychiatry, 34, 415-426.

Lejars, F. (1912). Ce qu'il faut penser des dangers de la bande d'Esmarch. Semaine Médicale, 32, 505-506.

Lundborg, G. (1970). Ischemic nerve injury. Scandinavian Journal of Plastic and Reconstructive Surgery, Suppl. 6.

Mayer, R. F., and Denny-Brown, D. (1964). Conduction velocity in peripheral nerve during experimental demyelination in the cat. Neurology (Minneap.), 14, 714-726.

McLeod, J. G., and Wray, S. H. (1967). Conduction velocity and fibre diameter of the median and ulnar nerves of the baboon. Journal of Neurology, Neurosurgery, and Psychiatry, 30, 240-247.

Moldaver, J. (1954). Tourniquet paralysis syndrome. Archives of Surgery, 68, 136-144.

Ochoa, J., Danta, G., Fowler, T. J., and Gilliatt, R. W. (1971). Nature of the nerve lesion caused by a pneumatic tourniquet. Nature, 233, 265-266.

Richards, R. L. (1954). Neurovascular lesions. In Peripheral Nerve Injuries. Edited by H. J. Seddon. M.R.C. Special Report Series No. 282. H.M.S.O.: London.

Seddon, H. J. (1943). Three types of nerve injury. Brain, 66, 237-288.

Speigel, I. J., and Lewin, P. (1945). Tourniquet paralysis. Journal of the American Medical Association, 129, 432-435. 